[Jpn. J. Agric. Econ. Vol.19, pp.31-36, 2017]

\title{
Cost-Benefit Analysis of Cultivating Three Major Crops and Its Implication to Agricultural Extension Service: A Case Study in North-West Ethiopia
}

\author{
Asres Elias $^{1 *}$, Makoto Nohmi ${ }^{1}$ and Kumi Yasunobu ${ }^{1}$
}

The aim of this study is to conduct cost-benefit analysis of major crops- maize, wheat, and teff targeted by agricultural extension service in North-West Ethiopia. Results reveal that Return On Investment (ROI) of major crops ranges from marginal to nil. However, ROI of maize is relatively better than teff and wheat. On average agricultural extension program participants generate 37.89 Ethiopian Birr from every 100 Birr invested for maize production, whereas ROI for teff is about 3 Birr and even further worse to wheat which has incurred a loss. Therefore, to make the crop production profitable, the current agricultural extension service should give consideration to the associated production costs and introducing affordable labor saving farm technologies remain important.

Key words: return on investment, agricultural extension, Ethiopia

\section{Introduction}

For farmers, the provision of an economic incentive is a highly important factor in decisions to adopt or reject a new technology. Besides, cost of production data can provide useful information to farmers, governments and policy makers. It can inform on a broad range of issues about agricultural resource use, production practices and inputs, farm costs and financial conditions, and well-being of farm households. Furthermore, an effective cost of production program can inform on the management tools and equipment utilized in the production process. It will also inform on what it costs to produce agricultural commodities and the income position of the farm household.

Ethiopia's most recent attempt to estimate the cost of production was in 1986 (Lys Peter, 2010). During this time instead of using a sample survey, the methodology used regional agriculture extension workers to estimate input use and prices based on their individual knowledge and farming practices in the local area. This approach was misguided as it relied extensively on the personal opinion of the field extension workers. Hence, data must be collected at household level so as to accurately estimate unpaid labour and the opportunity costs of capital used in the production process.

On the other hand, increasing farm productivity and income (Kassa, 2008; Gebremedhin et al., 2009; Asfaw et al.,
2012) are among the objectives of agricultural extension (AE) program in Ethiopia. However, in spite of taking measures to achieve high rate of adoption of improved farm technologies and promotion of yield enhancing, little or no attention has been given to return to investment in the production process (Beshir and Nishikawa, 2012). Moreover, our previous studies (Elias et al., 2013, 2014) on the impact of agricultural extension service on farm productivity and technical efficiency revealed that the extension program had marginal effect on farm productivity whereas insignificant effect on farmers' technical efficiency. However, its effect with its current structure and input could have tripled had there been no bias related to extension program participation. Besides about $45 \%$ of extension participant farmers are not satisfied with the program (Elias, et al., 2015). Hence, all these led us to look further the extension program in terms of return to investment or economic incentive. Therefore, the aim of this study is to conduct cost-benefit analysis of major crops targeted by agricultural extension service in NorthWest Ethiopia through application of Return on Investment (ROI) analysis method.

\section{Research methodology}

1) Description of the study area

This study was conducted in three selected kebeles ${ }^{1)}$ (peasant associations) i.e., Enerata, Kebi and Wonka in 
Gozamin district, Amhara Regional State, Ethiopia. It is found at about a distance of $265 \mathrm{~km}$ far from Bahir Dar city, the Regional capital, and at about $300 \mathrm{~km}$ from Addis Ababa city, the national capital. The district has a total area of $1,217.8 \mathrm{~km}^{2}$ and an estimated population of 133,856 , out of which $98 \%$ are living in rural areas (CSA, 2008). About 95\% of total crop production is rainfall dependent (Benin, 2006). Generally, the district has a big potential for agriculture due to its agro-ecological diversification and dependable rainfall and optimum temperature.

The economy of the district is based on plough-based and labour intensive agriculture, which depends mainly on meher rain (main rainy season). Main crops grown in the district in order of abundance include teff), wheat, maize, barely, check pea, soya bean, oats, niger seed (Neug) and lentil. Teff, maize, wheat, barley, sorghum and millet are dominant which cover about $80 \%$ of area under grain crops (CSA, 2012; Lys, 2010).

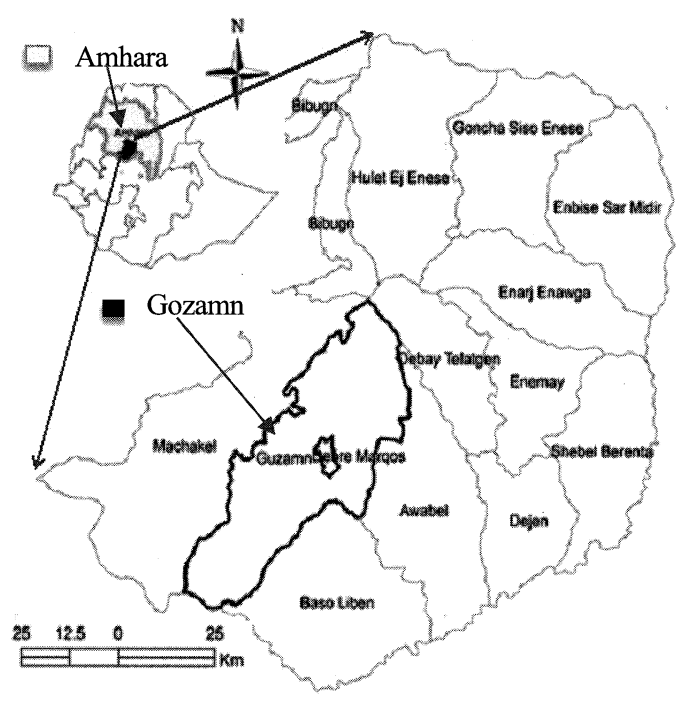

Figure 1. Location map of the study area

\section{2) Sampling and data source}

The three studied kebeles were randomly selected out of the total 25 kebeles found in the district. A multi-stage stratified random sampling technique was employed to select a total of 300 farm households. First, farmers in each selected village were stratified into two groups as participant and nonparticipant of the extension program. The groups were identified from a list made available by the front-line extension workers, and then the information was confirmed by the farmers. Second, the two groups obtained from the first stage sampling were further stratified in to male and female headed households to ensure, as much as possible, representation of female-headed households in the sample. Data were collected both at household and plot level using structured and pre-tested questionnaire. The household data consists of demographic characteristics of household head, resource endowment, use of credit, membership in farmers' organization and involvement in kebele administration. The plot level data consists of information on the intensity of input use (improved seed, inorganic fertilizer, compost and agro chemicals for pest and weed control), plot soil quality, plot slope, farm management practice (such as ploughing frequency) and amount of yield obtained during the 2011/12 main agricultural season.

\section{3) Methods of analysis}

Benefit-cost ratio and return-on-investment values help communicate the value of extension programs to society and key stakeholders (Jayaratne, 2012). The ROI value is more powerful than the benefit-cost ratio because the ROI value shows the net return for a $\$ 100$ investment. It implies the ainitial investment. This study also employed ROI to make comparison between $\mathrm{AE}$ participant and non-participant farmers in terms of their ROI. However, these sub-samples are unlikely to represent unbiased representations of the population. If farmers choose to participate in the $\mathrm{AE}$ program based on their expected performance, the two subsamples will systematically differ with respect to certain farm and household characteristics (different factors are explicitly discussed in Elias et al., 2013, 2014). If these factors influence farmer's propensity to participate in the $\mathrm{AE}$ program, they are also likely to influence farmer's production and cost-benefit performance. Consequently, if selection bias is ignored in the estimation of separate ROI, the result will be biased and difficult to relate ROI values with AE program. To deal with the potential bias, this study used matched samples obtained through propensity score matching in our previous study. Matching is a widely used non-experimental method of evaluation that can be used to estimate the effect of a particular program (Smith \& Todd, 2005; Caliendo \& Kopeinig, 2008). This method compares the outcomes of

2) A small cereal that is cultivated almost exclusively in Ethiopia, used mainly to make enjera a pancake like staple food. 
program participants with those of matched non-participants, where matches are chosen on the basis of similarity in observed characteristics. Suppose there are two groups of farmers indexed by participation status $\mathrm{P}=0 / 1$, where $1(0)$ indicates farms that did (not) participate in a program. Denote by $y_{i}^{1}$ the outcome is conditional on participation $(\mathrm{P}=1)$ and by $y_{i}^{0}$ the outcome conditional on non-participation ( $\mathrm{P}$ $=0$ ). Data on participants are available whereas data before participation is not available due to lack of baseline data but can be generated from matched non-participants which helps to answer the question: 'How much did farms participating in the program benefit compared to what they would have experienced without participating in the program?' (details are found in Elias et al., 2013).

\section{Results and discussion}

\section{1) Bio-physical characteristics of respondents}

As shown in Table 1 there is significant difference between AE participants and non-participants in terms of household characteristics and resource endowment before matching is employed. Moreover, participation in $\mathrm{AE}$ program is strongly associated with the household's demographic characteristics and resource endowment as well as membership in farmers' organization and involvement in kebele administration (Elias et al., 2013). This substantiates the necessity of using matched samples to compare costbenefit of $\mathrm{AE}$ participants and non-participants. The balancing test shown in our previous study (Elias et al., 2013) indicates that the covariates of the two matched groups are well balanced in contrast to the unmatched samples presented in Table 1 .

\section{2) Return on investment of teff, maize and wheat}

Due to differences in quantity of inputs used and other factors, production costs will vary from farm to farm. Price shifts for inputs can also change production costs in both the short and long run. Nevertheless, estimation of the ROI values in this study are not affected by variation in local price and marketing time. Because the data used reflect cost of purchased inputs and return to land estimated using average market price recorded during all months of 2012 whereas same year wage price were used to calculate labor resources including family, hired and oxen labour per hectare collected in terms of person/oxen day (amount of work done by one person/ox in one working day) for each agricultural activity from land preparation to storage of production respectively. The purpose of including unpaid labor as a cost of production is to understand the income forgone by not working off-farm activities such as unskilled off-farm wage employment which is mostly available opportunity in Ethiopia (Bezu et al., 2012). According to Davis (2003) and Woldehanna (2000), off-farm labor income accounts for up to 20-35 percent of total farm household income in Ethiopia.

\section{3) Return on investment of maize production}

The total production cost (Table 2) for cultivating one hectare of maize is estimated at about 9236.46 Birr $^{3}$ and 7450.12 Birr for AE participants and if they were not participants respectively. The major maize production costs incurred by $\mathrm{AE}$ participants are family labour (37\%) followed by oxen labour (42.7\%) and chemical fertilizer $(15.7 \%)$. The same trend in terms of cost distribution is observed if they would not become AE participant. Maize production is not oxen-labour intensive compared to teff and wheat. On average $\mathrm{AE}$ participants $\mathrm{ROI}$ of maize production is $37.89 \%$ per hectare, this implies that every 100 Birr invested or spent in maize production generates 37.89 Birr, whereas if they were not participant the profit would be reduced to 25.95 Birr. The ROI variation might be mainly attributed to the type of seed used. About $90 \%$ of $\mathrm{AE}$ participants used improved seed whereas only $27 \%$ of nonparticipants used improved maize seed as a result significant yield per hectare disparity is observed.

\section{4) Return on investment of teff production}

Unlike maize production, and contrary to the expectation, ROI value of teff obtained by AE participants is lower than if they were not participants. From every 100 Birr invested on teff production, participants generate about 3 Birr whereas they would generate about 5 Birr if they were not participant of AE. But for both cases ROI is very low considering the high market price of teff compare to other crops. This might be due to the labour intensive nature of teff production in Ethiopia which demands farmers to invest more on labour. Oxen and family labour (about 54\%, 18\% for participants and $57 \%, 19 \%$ for non-participants respectively) and chemical fertilizer (about $10.7 \%$ and $8 \%$ respectively) costs accounted the largest share from the total cost for both groups.

3) Birr is Ethiopian currency ( $\$ 1 \sim 17$ Birr in 2012 and now 22 Birr). 
Table 1. Descriptive statistics of households $(n=300)$ before matching

\begin{tabular}{lccccccc}
\hline & All sample & \multicolumn{3}{c}{ Participant } & \multicolumn{3}{c}{ Non-participant } \\
\hline Variables & Mean & SD & Mean & SD & Mean & SD & P-value \\
\hline Age of Household head $(\mathrm{HH})$ (years) & 45.7 & 10.07 & 45.45 & 10.02 & 46.09 & 10.14 & 0.303 \\
Sex of HH $(1=$ male, $0=$ female) & 0.82 & 0.38 & 1.00 & 0.00 & 0.54 & 0.49 & 0.000 \\
Education of HH $(1=$ literate, $0=$ illiterate) & 0.5 & 0.5 & 0.68 & 0.47 & 0.24 & 0.43 & 0.000 \\
Family size & 5.77 & 1.92 & 6.35 & 1.81 & 4.89 & 1.74 & 0.000 \\
Available family labor (adult equivalent) & 2.98 & 1.06 & 3.22 & 1.03 & 2.61 & 1.01 & 0.000 \\
Owned land size (hectare) & 1.34 & 0.63 & 1.53 & 0.6 & 1.05 & 0.57 & 0.000 \\
Owned livestock (Tropical Livestock Unit) & 7.14 & 3.92 & 8.91 & 3.83 & 4.48 & 2.18 & 0.000 \\
Use of credit previous year $(1=$ yes, $0=$ no) & 0.16 & 0.37 & 0.17 & 0.37 & 0.16 & 0.37 & 0.839 \\
Number of training received for the last three years. & 3.79 & 5.31 & 5.72 & 6.08 & 0.89 & 1.1 & 0.000 \\
Membership in farmer's organizations $(1=$ yes, $0=$ no) & 0.81 & 0.39 & 0.96 & 0.21 & 0.58 & 0.49 & 0.000 \\
kebele administration work $(1=$ yes, $0=$ no) & 0.25 & 0.44 & 0.46 & 0.49 & 0.01 & 0.1 & 0.000 \\
\hline
\end{tabular}

Note:1) SD refers standared deviation.

\section{5) Return on investment of wheat production}

Return on investment of wheat production is negative, for both participants and if they were not participants of $\mathrm{AE}$ program. The result in Table 3, indicated that AE participants on average would loss about 19 Birr if they were not participant. But even with their participation they are not profitable; they loss about 1 Birr from each 100 Birr invested for wheat production. According to the extension workers of the study area, there was wheat production loss during 2011/12 agricultural season due to the use of low quality improved seed and wheat leaf rust. This might be the major reasons for the negative ROI of wheat.

\section{6) ROI value implications for agricultural extension}

The estimated ROI values evidently shown that $\mathrm{AE}$ participants' profit from maize production is marginal and also they did not gain profit from teff and wheat crops through their participation in AE. Unlike the priority set by the extension program to maximize AE participants' income, they are not able to make profit from farming due to marginal yield increase and high production costs. For instance average teff yield observed from extension participants (16 quintal/ha) is less by half from the extension targets and research station yield (20-32 quintal/ha). Similarly, the yield

Table 2. Return on investment/hectare of maize production

\begin{tabular}{|c|c|c|c|c|c|c|}
\hline \multirow{2}{*}{ Cost-benefit indicators } & \multicolumn{2}{|c|}{ All (188) } & \multicolumn{2}{|c|}{ Participant (79) } & \multicolumn{2}{|c|}{ Non-participant (109) } \\
\hline & Mean & $\%$ cost & Mean & $\%$ cost & Mean & $\%$ cost \\
\hline Yeild (quintal/ha) & 21.38 & & 25.3 & & 18.52 & \\
\hline A: Gross production (ETH.Birr/ha) & 10792.52 & & 12736.3 & & 9383.72 & \\
\hline \multicolumn{7}{|l|}{ B: Production cost/ha } \\
\hline Family labour (Person day (Birr)/ha & 3130.6 & 38.2 & 3415.6 & 37.0 & 2923.8 & 39.2 \\
\hline Hired labour (Person day (Birr)/ha & 45.2 & 0.6 & 32.4 & 0.4 & 54.4 & 0.7 \\
\hline Oxen labour (Oxen day (Birr)/ha & 3478.3 & 42.4 & 3945.2 & 42.7 & 3139.5 & 42.1 \\
\hline Chemical fertlizer (Birr)/ha & 1185.47 & 14.5 & 1447.67 & 15.7 & 995.44 & 13.4 \\
\hline Seed (Birr)/ha(purchased and owned) & 88.71 & 1.1 & 89.97 & 2.6 & 87.79 & 1.2 \\
\hline Agrochemicals (Birr/ha) & 0.0 & 0.0 & 0.0 & 0.0 & 0.0 & \\
\hline Sharecropping/ha (land rent cost) & 272.9 & 3.3 & 305.62 & 3.3 & 249.19 & 3.3 \\
\hline C: Total production cost/ha & 8201.18 & & 9236.46 & & 7450.12 & \\
\hline D: Net value benefit/ha (A-B) & 2591.32 & & 3499.84 & & 1933.6 & \\
\hline E: Return on investment/ha (D/C*100) & $31.60 \%$ & & $37.89 \%$ & & $25.95 \%$ & \\
\hline
\end{tabular}


Table 3. Return on investment/hectare of teff production

\begin{tabular}{lcccccc}
\hline \multirow{2}{*}{ Cost-benefit indicators } & \multicolumn{2}{c}{ All (335) } & \multicolumn{2}{c}{ Participant (152) } & \multicolumn{2}{c}{ Non-participant (183) } \\
\cline { 2 - 6 } & Mean & \% cost & Mean & $\%$ cost & Mean & \% cost \\
\hline Yeild (quintal/ha) & 13.98 & & 15.72 & & 12.55 \\
A: Gross production (ETH.Birr/ha) & 12165.80 & & 13671.91 & & 10914.78 \\
B: Production cost/ha & & & & & \\
Family labour (Person day (Birr)/ha & 2182.60 & 18.64 & 2384.60 & 17.96 & 2014.60 & 19.38 \\
Hired labour (Person day (Birr)/ha & 145.40 & 1.24 & 53.00 & 0.40 & 222.00 & 2.14 \\
Oxen labour (Oxen day (Birr)/ha & 6512.80 & 55.61 & 7210.70 & 54.31 & 5933.20 & 57.08 \\
Chemical fertlizer (Birr)/ha & 1118.15 & 9.55 & 1420.05 & 10.69 & 867.39 & 8.34 \\
Agrochemicals (Birr/ha) & 28.33 & 0.24 & 32.87 & 0.25 & 24.56 & 0.24 \\
Sharecropping/ha (land rent cost) & 1409.07 & 12.03 & 1852.57 & 13.95 & 1025.30 & 9.86 \\
C: Total production cost/ha & 11711.69 & & 13277.75 & & 10395.23 & 2.96 \\
D: Net value benefit/ha (A-B) & 454.11 & & 394.16 & & 519.55 & \\
E: Return on investment/ha (D/C*100) & $3.88 \%$ & & $2.97 \%$ & & $4.99 \%$ &
\end{tabular}

levels attained by participant farmers for wheat and maize were less by $1 / 3$ from the set target for the corresponding crops (43-58 quintal/ha and 70-107 quintal/ha respectively). In addition, family, oxen labour and chemical fertilizer accounted the highest share from total production cost. As a result of low productivity, high production costs, limited use of modern inputs, and minimal levels of commercialization, most of farmers in Ethiopia are susceptible to poverty and chronic food insecurity. The current (2015) prevailing drought that expose many people to depend on food aid can be a good indicator for this situation.

On the other hand, enabling farmers to keep their farm records is among the goals of agricultural extension in Ethiopia at large and in the study area in particular. However, this is not a common practice in the study area. Only 3 farmers out of 150 participant farmers were able to record their farm expenses and benefits. Lack of awareness, experience and low levels of education could take the lion share for farmers' failure to keep farm records. Besides, unpaid labor costs such as family and oxen labour are not considered as real cost by farmers as a result they might not notice how much farm profit they loss due to investing more on unpaid labour. Further, much of their time that could be used for other income generating activities is consumed in

Table 4. Return on investment/hectare of wheat production

\begin{tabular}{|c|c|c|c|c|c|c|}
\hline \multirow{2}{*}{ Cost-benefit indicators } & \multicolumn{2}{|c|}{ All (132) } & \multicolumn{2}{|c|}{ Participant (57) } & \multicolumn{2}{|c|}{ Non-participant (75) } \\
\hline & Mean & $\% \operatorname{cost}$ & Mean & $\% \operatorname{cost}$ & Mean & $\% \operatorname{cost}$ \\
\hline Yeild (quintal/ha) & 16.05 & & 19.25 & & 13.61 & \\
\hline A: Gross production (ETH.Birr/ha) & 10445.59 & & 12532.70 & & 8859.39 & \\
\hline \multicolumn{7}{|l|}{ B: Production cost/ha } \\
\hline Family labour (Person day (Birr)/ha & 2123.40 & 18.19 & 2248.60 & 17.74 & 2028.20 & 18.44 \\
\hline Hired labour (Person day (Birr)/ha & 106.00 & 0.91 & 35.00 & 0.28 & 160.00 & 1.45 \\
\hline Oxen labour (Oxen day (Birr)/ha & 6048.00 & 51.80 & 6349.00 & 50.09 & 5819.80 & 52.91 \\
\hline Chemical fertlizer (Birr)/ha & 1626.53 & 13.93 & 2032.92 & 16.04 & 1317.67 & 11.98 \\
\hline Seed (Birr)/ha(purchased and owned) & 945.69 & 8.10 & 1048.58 & 8.27 & 867.49 & 7.89 \\
\hline Agrochemicals (Birr/ha) & 20.79 & 0.18 & 33.05 & 0.26 & 11.47 & 0.10 \\
\hline Sharecropping/ha (land rent cost) & 805.53 & 6.90 & 928.91 & 7.33 & 711.76 & 6.47 \\
\hline C: Total production costha & 11675.94 & & 12676.06 & & 10999.53 & \\
\hline D: Net value benefit/ha (A-B) & -1230.35 & & -143.36 & & -2140.14 & \\
\hline E: Return on investment/ha $\left(\mathrm{D} / \mathrm{C}^{*} 100\right)$ & $-10.54 \%$ & & $-1.13 \%$ & & $-19.46 \%$ & \\
\hline
\end{tabular}


farming. Family labour is critical input in agricultural production as well as in generating off-farm income to improve household well-being and source of survival especially in areas where annual production is not enough for household consumption. However, the current extension program is not working towards improving labour and cost efficiency apart from focusing on mass distribution of chemical fertilizer and to a certain extent on improved seeds.

\section{Conclusions}

This study clearly revealed that ROI of major crops targeted by the extension program in the study area is almost negligible. However, ROI of maize is relatively better than teff and wheat due to its low oxen labour intensive nature. On average AE participants generate 37.89 Birr from every 100 Birr invested for maize production and this would be reduced to $25.95 \mathrm{Birr}$ if they were not become AE participant. ROI of teff is about 3 Birr for AE participants while if they were not participant it would be about 5 Birr and wheat production incurs a loss. Therefore, to make the crop production profitable the current agricultural extension service should give high attention to the cost and benefit of farming in the study area.

Moreover, the labour intensive nature of agriculture in the study area do not paid off farmers' effort in farming. Especially human and oxen labour exposed them to higher production costs. Thus, labour efficient farming practices shoud be introduced through farmer training centers on top of expanding labour saving technologies. In addition, the program should consider benefit oriented alternatives for farmers. For instance, arrangement of affordable (subsidized) rental farm machineries via cooperatives/other stakeholders can contribute to reduce labor costs and improve labor efficiency inturn improve the rewards of farming.

\section{References}

Asfaw, S., B. Shiferaw, F. Simtowe and L. Lipper (2012) Impact of Modern Agricultural Technologies on Smallholder Welfare: Evidence from Tanzania and Ethiopia, Food Policy 37: 283-295.

Benin, S. (2006) Policies and programs affecting land management practices, input use, and productivity in the highlands of Amhara Region, Ethiopia. In J. Pender, F. Place, \& S. Ehui (Eds.), Strategies for Sustainable Land Management in the East African Highlands. IFPRI, Washington, D. C.

Beshir, B. and Y. Nishikawa (2012) Cost-Benefit Analysis of SmallScale Onion and Tomato Farming in Melkassa Area: Central Rift
Vally of Ethiopia, Tropical Agricultural Development 56(4):143150.

Bezu, S. Barrett, C. B. and S. T. Holden (2012) Does the Nonfarm Economy Offer Pathways for Upward Mobility? Evidence from A Panel Data Study in Ethiopia, World Development, 40(8):1634-1646. Caliendo, M., and S. Kopeinig (2008) Some Practical Guidance for the Implementation of Propensity Score Matching. Journal of Economic Surveys 22: 31-72.

CSA (Central Statistical Agency) (2008) Statistical abstract 2008, Central Statistical Agency, Addis Ababa, Ethiopia.

CSA (2012) Agriculture in Figures: Key findings of the 2009/102011/12 agricultural sample surveys for all sectors and seasons, Country Summary, Addis Ababa, Ethiopia.

Davis, J. R. (2003) The Rural Non-Farm Economy, Livelihoods, and Their Diversification: Issues and Options. World Bank.

Elias, A., M. Nohmi, K. Yasunobu and A. Ishida (2013) Effect of Agricultural Extension Program on Small Holders' Farm Productivity: Evidence from Three Peasant Associations in the Highlands of Ethiopia, Journal of Agricultural Sciences 5(8):163-181. Elias, A., M. Nohmi, K. Yasunobu and A. Ishida and A.D. Alene (2014) The Effect of Agricultural Extension Service on the Technical Efficiency of teff (Eragrostistef) Producers in North Ethiopia, American Journal of Applied Sciences 11: 223-239.

Elias, A., M. Nohmi, K. Yasunobu, and A. Ishida (2015) Farmers' Satisfaction with Agricultural Extension Service and Its Influencing Factors: a Case Study in North-West Ethiopia, Journal of Agricultural Science and Technology 17: 39-53.

Gebremedhin, B., Jalata, M. and Hoekstra, D. (2009). Smallholders, Institutional Services, and Commercial Transformation in Ethiopia, Journal of Agricultural Economics 40: 773-787.

Gozamin Woreda Finance and Economic Development sector Office Document (2010). Allocation of budget from 2003 to 2010, East Gojam zone, Amhara Regional State.

Jayaratne, K. S. U (2012) Learn How to Analyze Cost-Benefits of Extension Programming. State Leader for Program Evaluation, North Carolina State University.

Kassa, H. (2008). Agricultural extension in Ethiopia: Historical evolution, relevant policies and challenges, in Taye Assefa (ed.), Digest of Ethiopia's National Policies, Addis Ababa: Eclipse Printers. Lys, P. (2010) The Current State of Cost of Production Estimates a Review of Country Practices in Ethiopia, Mali and Zambia.. http://www.fao.org/economic/ess/ess-events/expert-production/en/ [Accessed 4 December 2015].

Smith, J., and P. Todd (2005) Does Matching Overcome Lalonde's Critique of Non-experimental Estimators? Journal of Econometrics 125: 305-353. 